\title{
Article
}

\section{Seeing for yourself: How 'ambient information' shapes parental attitudes to higher education}

Canovan, Cherry and Luck, Christiane

Available at http://clok.uclan.ac.uk/25860/

Canovan, Cherry ORCID: 0000-0002-9751-5646 and Luck, Christiane (2018) Seeing for yourself: How 'ambient information' shapes parental attitudes to higher education. Widening Participation and Lifelong Learning, 20 (4). pp. 148-168. ISSN 1466-6529

It is advisable to refer to the publisher's version if you intend to cite from the work. http://dx.doi.org/10.5456/NVPLL.20A.148

For more information about UCLan's research in this area go to http://www.uclan.ac.uk/researchgroups/ and search for <name of research Group>.

For information about Research generally at UCLan please go to http://www.uclan.ac.uk/research/

All outputs in CLoK are protected by Intellectual Property Rights law, including Copyright law. Copyright, IPR and Moral Rights for the works on this site are retained by the individual authors and/or other copyright owners. Terms and conditions for use of this material are defined in the policies page.

\section{CLoK}

Central Lancashire online Knowledge www.clok.uclan.ac.uk

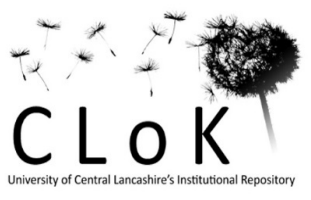




\title{
Seeing for yourself: How 'ambient information' shapes parental attitudes to higher education
}

\author{
Cherry Canovan, University of Central Lancashire (corresponding \\ author)
}

Christiane Luck, University of Central Lancashire

Email: ccanovan@uclan.ac.uk

\begin{abstract}
Parental attitudes are a key determinant of whether a young person goes on to university, but parents from disadvantaged areas sometimes feel ill-equipped to advise their children. This study looks at whether visiting a university campus for a fun, informal event can alter parents' feelings of comfort with, and knowledge about, higher education. Using a mixed-methods case study conducted at an English university-based science festival, we found that parents from areas of greater deprivation underwent a more significant positive shift in attitude towards university than those from less deprived areas. We use the concept of 'ambient information' to describe the information collected by immersion in a university setting in a neutral context; we found that this information worked to make university seem 'real' or 'achievable' to parents. We also found that participants gathered knowledge in key areas such as the types of facilities and courses that universities offer. We conclude that informal events on university campuses can have valuable benefits for widening participation. However organisers face the challenge of improving attendance at such events by under-represented groups without impacting on their relaxed nature.
\end{abstract}

Key words Science festival; widening participation; public engagement; science communication; ambient information; higher education.

\section{Introduction}

Improving higher education participation amongst young people from disadvantaged backgrounds is a key policy challenge both internationally and in the UK specifically. The most recent government figures at the time of writing show that the gap in enrolment between pupils receiving free school meals and those who do not has remained almost static over the last decade, varying between 17-19\% (Department for Education, 2017: 1). In response to this challenge, the recent Higher Education and Research Act 2017 contains a renewed emphasis on access and equality of opportunity ${ }^{\mathrm{i}}$. 
Universities have made significant efforts to widen participation amongst diverse societal groups, using targeted programmes such as mentoring, careers sessions and summer schools. This paper will, however, focus on the impacts of broader-brush initiatives not related to higher education promotion which aim to attract large numbers of people, and particularly families, on to campuses.

We focus specifically on the impacts that such initiatives can have on parents with lower socioeconomic status, both in terms of their knowledge of what facilities and courses are available at a university, and in terms of their feelings about whether university is a place where they 'belong'. We introduce the concept of 'ambient information' to describe how attendees at such events are able to organically absorb information about the higher education setting without any overt pressure to do so.

One type of initiative which is growing in popularity is the universitybased science festival. Institutions as varied as Cambridge, the University of Central Lancashire, Imperial College London and Bath universities host such festivals, which invite the public into their spaces to find out about science in a fun and engaging way. Using data gathered from one festival, we argue that ambient information gleaned at such events can affect parental attitudes to higher education, thus increasing the likelihood of them encouraging their children's future participation.

\section{Theoretical framework}

The theoretical underpinning for this study draws on several bodies of work, including 1. Bourdieusian concepts of habitus, capital and field; 2. Problematic concepts of disadvantage; 3 . Research focusing on the role of parents in decision-making about higher education participation; and 4. Theories of 'hot', 'cold' and 'warm' information, introducing our extension to 'ambient' information.

\section{Habitus, capital and field}

It is useful to consider attitudes to higher education through the prism of the influential sociologist Pierre Bourdieu's concepts of 'habitus', 'capital' and 'field'. Habitus can loosely be described as one's sense of one's place in the world, determined by life experiences and factors such as class and race, and is considered to be a key driver of behaviour and decision-making. According to Swartz:

"Habitus... adjusts aspirations and expectations according to the objective probabilities for success or failure common to the members of the same class for a particular behavior... Habitus orients action according to anticipated consequences.” (Swartz, 2002: 64S) 
Habitus is not fixed, but is created from a continual accumulation of our life experiences. This therefore gives us the opportunity to influence attendees' habitus - their vision of themselves, their place, and the possibilities for their future - and thus potentially affect their future actions. From the perspective of this study, the crucial aspect of habitus is whether parents view university as a place 'for' them and their children.

A child's habitus is strongly influenced by their family experiences; in fact Archer et al. have formalised the concept of 'family habitus' “.... as a means for capturing the family as a unique site within which complex 'ways of being' in the world are developed,” (Archer et al. 2012: 886). There is an interplay between the child's experience and the parents' experience, creating a shared sense of who 'they' are. Thus, impacts on the parent affect the child's habitus, and vice versa; shared experiences have the capacity to produce a shift in the collective habitus.

Another key concept, that of 'capital', includes assets such as knowledge and social and economic resources. Of interest to this study are factors such as knowledge of what courses and facilities might be available at a university. The interplay between habitus and capital in a specific 'field' or setting such as education determines an individual or family's place in that setting.

\section{Problematic discourses of disadvantage}

In discussing widening participation and the obstacles faced by some families in accessing higher education, it is useful to reflect on the potential problems that can arise from a dialogue centred around notions of disadvantage. In particular, it is important to guard against what Valencia (1997: xi) refers to as "deficit thinking [which] overwhelmingly locates school failure causes in students and their families".

In terms of higher education, Smit (2012: 370) notes that "The dominant thinking... attempts to understand student difficulty by framing students and their families of origin as lacking the academic, cultural and moral resources necessary to succeed..." Smit goes on to argue that this deficit thinking can lower teacher expectations and teaching practice through unjust labelling and stigmatisation. This positioning of certain groups of students as less likely to succeed can, Smit notes, "perpetuate the stratification of society”.

In considering the difficulties faced by certain groups of students in accessing higher education, therefore, it is imperative that our actions do not contribute to the 'othering' of these groups. Neutral methods of engagement, which do not explicitly target underrepresented groups but which may disproportionately impact them, may therefore be of interest. 


\section{The role of parents}

A great deal of research (eg Archer, Hutchings and Ross, 2003; Bailey, 2015) has looked at the factors influencing less-advantaged young people in deciding whether to participate in higher education. A key factor that emerges is the influence of parents' views.

One study found that parents were the key group with whom young people discussed higher education, and that their advice was most likely to be listened to (Dodgson, 2004: 5-23). However parents in these groups may not feel well-equipped to advise their children about higher education, especially if they have no personal experience of it (Archer, Hutchings and Ross, 2003: 101; Pugsley, 1998: 78-82). In addition, some authors (Connor and Dewson, 2001: 40) suggest that working-class parents are more inclined to support whatever decisions a child makes rather than attempt to guide these decisions, within a paradigm of the child as the "'educational expert' within the family” (Reay and Ball, 1998: 435).

Bailey, who spoke to working class young people from low-income wards in the South Yorkshire town of Barnsley, notes that although there was evidence that participants' places of study were trying to give them an insight into university life,

“...it seems that the participants, in the main, craved for this information to be validated by their parent(s), which in the absolute majority of cases did not happen.” (Bailey, 2015: 185)

It is known that parents from more deprived backgrounds are not lacking in aspiration for their children; in the large-scale ASPIRES study, almost all pupils reported that their parents valued education (Archer et al. 2013: 1). However ASPIRES also found that parents from lower socioeconomic groups

"...were uncertain as to whether their children would be able to achieve their high aspirations, due to the challenges life presented," (Archer and DeWitt, 2017: 34).

The fact remains that disadvantaged young people are far less likely to go to university than the population on average. As Khattab (Khattab, 2015: 734) notes, high aspirations do not necessarily align with high expectations - in other words, to some people an aspiration may seem realistically achievable, while to others it may seem more of a 'hope'. It is therefore important to build high expectations among parents as well as pupils in order to increase the probability of their shared aspirations coming to fruition (Whitty, Hayton, and Tang, 2015: 44). Our study focuses explicitly on the impact of visiting a university for an informal event on parents' views and knowledge (capital).

\section{4. 'Hot', 'cold' and 'warm' information}


One way in which we can influence parental and family capital is by providing information which they may currently lack about what university involves, how it can be accessed, and the benefits it can confer. However it is important to note that young people and parents from different social backgrounds have been shown to respond differently to different types of information.

Ball and Vincent (1998: 377-394) make the distinction between 'hot' or 'grapevine' information, gleaned from personal contacts such as friends and relatives, and 'cold' or 'official' information, typically printed documents such as prospectuses. Although most parents make use of grapevine information, it is middle-class, professional parents who supplement such sources with 'cold' information.

Hutchings (Archer, Hutchings and Ross, 2003: 109) found a similar pattern among the young working-class people spoken to during a series of focus groups. Participants tended to rely on 'hot' knowledge, and 'cold' sources such as prospectuses were viewed with suspicion, being seen as self-serving.

Slack et al. extend the concept of 'hot' and 'cold' information to include 'warm' sources of information, typically encountered at university open days:

“...information from previously unknown university students, particularly from open days, is regarded as an important source of information... Such knowledge is not coming from socially embedded networks, but is seen as coming from persons with whom there is a perceived synergy, and... may be classed as 'warm'.” (Slack et al. 2014: 215)

\section{'Ambient' information}

We now propose extending the metaphor to describe the situation where potential students and their families visit universities for a reason not connected to HE recruitment. For such an occasion to arise, the visit needs to lack any intention to apply to university on the part of young people; it also, crucially, needs to be without any intent to recruit them on the institution's part. This allows information about the higher education environment to be collected in a neutral setting; we term this 'ambient information'. This information has the advantage of being available to all and therefore does not risk establishing any narratives of 'deficit' with respect to certain groups.

Ambient information may be deemed more trustworthy than cold information because it is collected by the recipient themselves without the involvement of an intermediary; however it may be more accurate than hot information because it is not distorted by the personal opinions of others. It is complementary to warm information; for example, visitors to an HE 
institution may meet staff or students who, without explicitly discussing university entrance, impress them favourably and add to the overall impact of the setting.

\section{Science festivals: research and impacts}

The concept of the science festival is relatively modern, with the first such formally-labelled event taking place in Edinburgh in $1989^{\mathrm{ii}}$. Over the last 30 years it has become a wide-reaching cultural phenomenon; at the time of writing, the UK Science Festivals Network (SFN) has more than 40 members. Research from 2011 (Bultitude, McDonald, and Custead, 2011: 165) found that worldwide, more than 5.6 million people were reached by science festivals annually, a figure that has almost certainly grown over the last few years. In 2015, members of the SFN recorded more than 900,000 interactions with members of the public ${ }^{\mathrm{iii}}$.

Science festivals vary in size from small local events to vast, multi-day programmes attracting 100,000 visitors. Despite this heterogeneity, they share common features: an atmosphere of fun, hands-on activities, the mingling of scientists with members of the public, and a concentration of effort that comes with their time-limited nature.

Despite the recent explosion of interest, it has been widely noted (Bultitude, 2014: 3; Jensen and Buckley, 2014: 561; Rose et al. 2017: 250) that little academic research has studied the aims and impacts of science festivals. The rich, immersive, multi-faceted nature of the science festival experience means that their impacts can be felt on a number of levels (Wiehe, 2014: 7), a phenomenon which is still being probed in the literature.

One aspect which has been shown to be important in participants' experiences of festivals is the physical location in which they are held. Previous research (Bultitude and Sardo, 2012; Riise and Alfonsi, 2014) has focused on the benefits of holding festivals in 'generic' locations, such as shopping centres, in engaging new audiences.

However the question that we pose is specific to university-based science festivals, and is intimately connected to their unique campus environments. Specifically, we are asking whether it is possible that attending festivals in these settings could have a measurable impact on attitudes to higher education, particularly among disadvantaged groups?

Festivals provide a rare opportunity for families to visit a university setting together while the children are still young; it could therefore provide information to parents about higher education at a point before their children turn to them for advice. The informality of the occasion, combined with the fact that the emphasis is not on recruitment, could provide a good example 
of 'ambient information' without the distrust that is sometimes engendered by perceptions that a university is trying to 'sell itself'.

The experience of physically visiting the campus and meeting staff and students associated with it may also be able to boost attendees' understanding of what a university 'is' or 'does', and allow them to feel that a university is somewhere that their children might aspire to.

\section{Methods}

In order to investigate the questions discussed above, we instigated a mixed-methods study at a UK campus-based science festival. This case study was intended to yield some preliminary indications as to the validity or otherwise of our thesis, within the context of an English university setting. It also enabled us to explore the use of a variety of methods to test their potential for elucidating the effects of 'ambient information'.

\section{The Lancashire Science Festival}

The fieldwork for this study was conducted at the 2017 edition of the Lancashire Science Festival (LSF). The LSF is a medium-sized science festival run annually since 2012. It is held at the Preston campus of the University of Central Lancashire over three days in June; the first two days are reserved for school parties, while the third, a Saturday, is open to members of the public. Total visitor numbers in 2017 were around 17,000, including fringe and associated events; the public day attracted more than 7,000 visitors.

The festival is largely aimed at primary-age children, and the overwhelming majority of public-day visitors attend in family groups. People travel from across the North West of England, from as far afield as Merseyside and Greater Manchester, although approximately half come from Preston and its immediate surroundings.

The festival programme includes large-scale shows (accommodating up to 480 people) held in the university's main lecture theatres, as well as smaller 'drop-in' and workshop sessions. In addition there are two 'show floors', large open areas full of stalls, each of which has a hands-on activity which children can explore at their own pace.

Because the festival is distributed across the campus, participants have the opportunity to see the university in an informal way as they walk between events. They can walk in and out of different teaching buildings, sit in lecture theatres and access locations such as labs and computer rooms, getting an overall view of the scale and facilities. 
Around 200 staff and student ambassadors provide support at the event, so members of the public come into contact with many individuals, particularly young adults, associated with the university. The university, however, runs no overt recruitment or marketing activity during the event.

\section{Study methodology}

The study employed a mixed-methods strategy involving pre-event and post-event questionnaires, on-the-day interviews and a focus group. This combinatory approach is designed to give a rich and detailed view of our participants' characteristics, perspectives and motivations and enables triangulation between qualitative and quantitative data, thus minimising the drawbacks of any single methodology. As Johnson and Onwuegbuzie note:

"both quantitative and qualitative research are important and useful. The goal of mixed methods research is not to replace either of these approaches but rather to draw from the strengths and minimize the weaknesses of both...” (Johnson and Onwuegbuzie, 2004: 14)

\section{Pre-event questionnaire}

Each group attending the festival was required to register, either online or in person on the day. As part of this process the person leading the group was asked to answer a brief questionnaire designed to determine relative deprivation, educational status and a measure of attitude to science $(\mathrm{n}=$ 1,724). As each group contained an average of 3.7 individuals, we received responses from $27 \%$ of attendees at this stage. Although relative numbers of children and adults are not recorded, organisers estimate that attendees are more than $50 \%$ children, meaning that at this stage we surveyed $54 \%$ or more of adult attendees.

Deprivation was extrapolated from postcode, using the Index of Multiple Deprivation (IMD), a UK-government tool which divides postcode areas into deciles on the basis of factors such as income, employment and education, with decile one the most deprived and 10 the least. This tool has been shown to correlate with educational disadvantage (Greaves and Crawford, 2013: 14).

\section{On-the-day interviews}

On-the-day interviews have the advantage to the researcher of eliciting responses while the subject is immersed in the science festival experience, thus providing immediacy of insight into visitor attitudes. A reduced level of self-selection of respondents is another methodological advantage. However this method also has drawbacks; it was necessary to limit interviews quite strictly in length, so as not to impact on visitor experience, 
and interviews were frequently conducted in noisy environments with the risk that parents/carers would be distracted by the necessity of supervising their children.

Structured interviews were conducted by a team of research assistants who spoke to adult visitors during the festival. Research assistants received training before the event designed to minimise mistakes and biases in the interview process.

The interview consisted of several Likert-scale questions combined with three open-ended questions to elicit further qualitative information. Some past investigations into visitors' experiences of science festivals have used only closed-ended responses (Jensen and Buckley, 2014: 562). Our format aimed to go further and elicit unprompted qualitative responses. The structure of the interview was designed to balance the desire of the researchers to probe respondents' attitudes with the desire of the organisers to avoid adverse impacts on the attendees' experience of the festival.

The dispersed nature of the festival events meant that it was difficult to systematically randomise the selection of subjects. Researchers were split into small groups of 2-4 and assigned to different venues. Some researchers spoke to people queueing for shows, in which case they were instructed to approach every fifth person in the line. Others were assigned to the 'show floors'; in this instance researchers simply approached parents who were waiting or observing.

Despite this, on measures of deprivation and educational status the sample appears highly representative. Of those interviewed ( $n=188), 45 \%$ had postcodes in IMD-deciles 1-5, compared with $44 \%$ of registrants who attended. Similarly, $66 \%$ of interviewees had a degree or equivalent, compared to $64 \%$ of registrants who attended.

\section{Post-event survey}

All attendees were sent a link to an online survey on the first working day after the festival, with responses allowed up to two weeks after the event. As well as research questions, organisers included several more 'functional' questions to evaluate the practicalities of event organisation. The research section comprised Likert-type questions enquiring about attitudes to university and science careers, together with open-ended questions to elicit thoughts and opinions.

The advantage of this aspect of the methodology is that respondents had had time to reflect on their experience at the point of completion and were answering at a time and in an environment of their choosing. This is reflected in the fact that the qualitative, open-ended questions were often answered at greater length than was possible during the on-the-day interviews. 
However the disadvantage of this method is the self-selection which is evident in the response rates. We did not ask the post-event respondents their educational status, but we did gather postcodes. These reveal that only $36 \%$ of post respondents (total $n=273$ ) had postcodes in $\mathrm{d} 1-5$, compared to $44 \%$ of registrants who attended. The results of this component of the data set are therefore skewed towards attendees from less deprived areas. We can, however, triangulate these findings with the on-the-day findings to elucidate common themes and impacts.

\section{Focus group}

After the initial results were analysed, a focus group was organised to probe reported positive impacts in more depth. On-the-day interviewees had been asked whether they would be willing to take part in further research. We sought participants who had reported some positive impact, either in terms of attitudes to science or attitudes to higher education, to researchers; we also looked for people who lived in central Preston (PR1 and PR2 postcodes) to avoid skewing the pool towards participants who were more able to travel. This left a potential pool of 46 participants, all of whom were invited to attend.

We felt that a smaller focus group would be appropriate, given that we were keen to get an in-depth appreciation of perceived impacts (Krueger and Casey, 2015: 68). Given the small size of the potential pool, we felt we would be unlikely to be able to convene more than one group. We therefore held one focus group with five participants, comprising $11 \%$ of the available pool. The group consisted of four women and one man from a range of educational and social backgrounds. Whilst the diversity of backgrounds did allow us to gather a variety of opinion, it would be meaningless to claim that such a small group could be 'representative' of festival attendees as whole. These contributions should be viewed rather as an opportunity to gather a deeper perspective on the experiences of individuals.

It is worth noting at this stage that we did not include participants who reported no positive impact; it would be interesting in a future piece of work to probe the experience of such individuals.

\section{Analysis}

Quantitative results were analysed using Microsoft Excel and qualitative results using NVivo. In the first stage, results from the Likert-scale questions were examined to gather quantitative information about views on higher education. Qualitative results were then analysed using inductive thematic analysis procedures; the material was first read and re-read to ensure familiarity, and then tagged with initial codes. These were then examined to develop overarching themes, and the codes revisited in the light 
of these. In addition, some qualitative data was quantized using numerical coding in Excel.

The quantitative and qualitative results were then considered as a whole and themes to be explored further in the focus group were identified. The focus group data was then transcribed and re-coded through an iterative process using both existing codes and new codes.

\section{Results}

Reaction to the festival was overwhelmingly positive, with comments denoting 'interest' and 'enjoyment' extremely common, as can be seen in Table 1 . This finding supports Jensen's thesis that “...the opportunity to encounter science in an 'exciting' or 'inspiring' context is a... commonly perceived benefit of attendance,” (Jensen and Buckley, 2014: 570.) The question addressed here is whether that sense of fun within the context of the festival can produce effects beyond mere enjoyment, but rather can help to change attitudes or create opportunities for the families who attended, particularly those from more deprived backgrounds.

\begin{tabular}{|l|r|r|l|}
\hline Class of words & Count & \multicolumn{1}{|c|}{$\begin{array}{c}\text { \% of total words } \\
\text { (three letters } \\
\text { plus, n=6,282) }\end{array}$} & \multicolumn{1}{|c|}{ Example words } \\
\hline Opportunities & 204 & 3.25 & $\begin{array}{l}\text { Opportunity, option, } \\
\text { help, open, access, } \\
\text { awareness, career }\end{array}$ \\
\hline Children & 195 & 3.10 & $\begin{array}{l}\text { Child, kid, son, } \\
\text { daughter }\end{array}$ \\
\hline Science & 188 & 2.99 & Science, sciences \\
\hline Enjoyment & 158 & 2.52 & $\begin{array}{l}\text { Fun, excitement, enjoy, } \\
\text { like, love, enthusiasm, } \\
\text { fantastic }\end{array}$ \\
\hline Interest & 140 & 2.23 & $\begin{array}{l}\text { Interest, engagement, } \\
\text { fascinated }\end{array}$ \\
\hline $\begin{array}{l}\text { Pre-existing } \\
\text { interest }\end{array}$ & 126 & 2.01 & Already, always \\
\hline University & 101 & 1.61 & University, uni \\
\hline Encouragement & 82 & 1.31 & Encouraged, inspiration \\
\hline Education & 56 & 0.89 & $\begin{array}{l}\text { Education, informative, } \\
\text { learning }\end{array}$ \\
\hline
\end{tabular}

Table 1: Most commonly mentioned clas of words in open-ended questionnaire and interview responses 


\section{Attendee profile}

Of registrants who attended and whose postcode we were able to analyse, $44 \%$ were from deciles $1-5$ and $56 \%$ from deciles $6-10$. When we compare the most and least deprived groups we find a greater disparity, with $25 \%$ from d1-3 and 41\% from d8-10.

LSF participants were much more likely than the general population to hold a university degree or equivalent. Of attendees, 64\% had a degree, compared to 27\% across England and Wales and 25\% across Lancashire ${ }^{\mathrm{iv}}$. For comparison, a recent study by Kennedy et al. of three UK science festivals found that between 71-80\% of attendees held a degree (Kennedy, Jensen and Verbeke, 1997: 4).

\section{Attitudes to higher education}

When asked by researchers at the festival whether they had ever thought that their children could go to university, $98 \%$ of parents agreed that they had thought so; there were no significant differences between social groups in this respect, although parents from less deprived areas were somewhat more likely to 'definitely’ agree with this statement (81\%:72\%). Qualitative responses also showed that many attendees considered it possible that their children would go to university; when we coded the open-ended responses from our combined data set for this, $27 \%$ indicated this view, with no significant differences between socio-economic groups. This is no surprise, as prior research shows that parents from all social groups have high aspirations for their children (Archer et al. 2013: 1).

However when participants were asked whether attending the festival had affected their views about young people in their care attending university, a significant difference emerged between social groups. Overall, 59\% of parents said that the experience had had a positive effect on their view of higher education. However visitors from IMD-d1-5 reported a more intense reaction; 35\% said that they felt "much more" positive about university following the experience, compared to $25 \%$ of those from IMD-d6-10, a result that is statistically significant at $\mathrm{p}<0.05$ ( $\mathrm{p}=0.027$ using a comparison of two proportions test).

This disparity in impact is supportive evidence for Archer and DeWitt's (2017: 34) finding that while parents from lower socio-economic groups had high aspirations for their children, they also felt greater uncertainty about whether these were realisable. Our data indicates that visiting the Festival helped parents from IMD-d1-5 feel more security about their aspirations for their children.

It is interesting to note that on the day, non-graduates reported a higher level of increased positivity than graduates, with $50 \%$ (30/60) reporting a positive effect compared to $38 \%$ (40/104) of graduates. Due to the fact that 
numbers were small, as educational status was not recorded for the postevent survey, this result cannot be regarded as statistically significant, but it is certainly suggestive.

Thematic analysis has identified several factors playing into this overall improved perception of the value of higher education, and particularly into the impact on parents and carers from more deprived communities. These themes were identified from views expressed by a wide range of participants from a variety of backgrounds; however while attendees from different socioeconomic groups experience events in the same way, these experiences may have different levels of impact depending on existing habitus and capital.

\section{Visiting a university}

The experience of physically visiting the campus was a theme that frequently arose among respondents. Typical comments were:

"[You] get to see the building and atmosphere, [which is] good for kids to experience."

"[You] get to see how [the] campus is set out and the facilities."

"I have lived in Preston for 15 years and had never been to the uni before but the facilities were fantastic.”

"My seven-year-old would not normally get to visit a university. This normalises the buildings and she can associate fun with higher education for a long time.”

"My nine-year-old son was amazed with the campus and lecture theatres and wants to go to uni now."

"My children got the chance to see the university and its buildings first hand, experiencing the lecture rooms and how the buildings are separated."

One parent from an area in IMD-decile 1 (most deprived) within a short walk of the university campus said: "[I've] never visited the uni before and it's not what I expected. [I] felt welcomed.”

In our focus group Sandrav, a mother with a large family living in an IMD-d1 area of Preston, told us that she had also never visited the university before, despite living less than a mile away. She described the strong impact that attending had had on her family, and when another participant, Helen, noted that the festival was “... definitely part of our calendar now, to come back each year," Sandra responded: "Yeah. Definitely, yeah.”

\section{Reality and accessibility}


A common theme among respondents was that attending the festival had made the idea of university "more real", "accessible" or "attainable". For example, one parent from an IMD d-3 area of Preston said they felt more positive about their child attending university after "chatting to staff and realising there is a possibility.” Other comments included:

"It's her dream, [and] the people manning the stalls made her feel it was achievable.”

"It makes university approachable."

"You can see that things are accessible."

\section{Knowledge of courses and facilities}

Gaining an insight into the opportunities and courses available at a university was another important theme in our interviews and questionnaire responses; in fact as Table 1 shows, the most commonly-used class of words in our qualitative responses were those denoting 'opportunities', indicating that attendance had provided concrete examples of how a young person can experience university. Comments included:

"I have always encouraged my son to get further education, but it was good to see the broad range of subjects they could study."

"My four children already aspire to going to university. The festival opens up the possibilities of what they could study."

"This helps them to see what's available and offers opportunities."

Lack of knowledge of the courses available was identified by focus group participants as a key barrier to attending university. Helen commented:

"It's sometimes an awareness of what you can do at university. People are beginning to realise that it's not just your subjects that you do at school but it's a lot broader than that... there's a lot to do with, 'oh, I don't want to do history' or 'I don't want to do geography' but not being aware of what else you could do.”

It is clear from the above comments that attending the festival went some way to bridging this knowledge gap.

\section{Discussion}

Although the overwhelming majority of participants told us they thought their child might go to university, we know that these aspirations are much less likely to come to fruition amongst the children of disadvantaged families. We also know that parental views and knowledge are one of the key factors in a young person's decision as to whether to participate in higher education. We are therefore interested in whether attending a broad- 
based public engagement event such as a science festival can shift the attitudes of parents within such families.

While a majority of all parents stated that their view of higher education was more positive following the event, parents from more deprived areas expressed this view significantly more strongly. We can examine the themes developed in the previous section to evaluate why this might be the case.

The experience of attending the festival appears to have affected both habitus - the feeling of 'where I belong' - and capital - for example, knowledge of available degree courses. Our concept of 'ambient information', can help us in considering why the experience was effective in this regard.

The first theme identified was the benefit of simply being in the university environment, which is a key component of what we term 'ambient information' - the experience of being immersed in a university setting so that we can find out what a university 'is'.

Although this theme was highlighted by parents from across the social spectrum, the data offers some suggestion that families with more existing educational capital see this information strand as of benefit to their children, rather than themselves, possibly because the parents already 'know' what a university 'is'.

Parents who have never experienced such an environment, on the other hand, such as focus group participant Sandra, potentially have much to gain from the experience. Sandra seemed to experience a shift in perception; she had previously never visited a university, but now she can envisage visiting one on a regular basis. From a Bourdieusian perspective, this shift in habitus towards a comfort with the conception of the university campus has the potential to affect her future behaviour when it comes to advising her children on the question of higher education.

Our second theme, notions of university as 'real', or 'achievable', raises an important distinction between high aspirations and high expectations. Although, as we have seen, most parents have high aspirations for their children, these are less likely to be accompanied by high expectations in families without existing educational capital. If we can shift these parents' mindsets from regarding higher education as a 'dream', to something that is solidly achievable, this has the potential to have a beneficial impact on their children's future participation, and this is what appears to have happened. "It has reaffirmed me," said one parent from an IMD-d2 area of Chorley. Another parent, from an IMD-d2 area of Preston, made the point well:

"We are very pro-education so have high expectations that our kids would attend university as a natural progression of their education. So attending such events helps us to reinforce this, and it is great to see and use parts of [a university] that would not normally be accessed by the public.” 
Again, this feeling of solidity has emanated from the experience of visiting the university, collecting ambient information, and meeting individuals associated with it. For example, a parent from an IMD-d1 area of Burnley, itself one of the most deprived districts in England ${ }^{\mathrm{vi}}$, commented: "Seeing so many members of the university expressing their enthusiasm and passion for their subject gives me an indication of the quality education aspiring students would receive.”

In this latter point we see the interplay between 'ambient' and 'warm' information. When asked by the organisers to name a positive aspect of the festival, 25\% of respondents volunteered that the students and staff involved were welcoming and helpful. Visitors did not discuss the university with the volunteers; this was explored during the focus group, and participants agreed that their only conversations were along operational lines, for example asking directions. This is the interaction between 'ambient information' and 'warm information' discussed in earlier sections; these student volunteers were viewed as friendly, fun and trustworthy, but rather than giving specific information about higher education, they formed part of the overall impression gleaned by visitors. The fact that they are viewed as approachable makes the university itself seem approachable.

The above themes act to influence habitus - to increase the participant's comfort in the university environment, to foster a sense of 'belonging here'. But another theme was the ability to gather concrete knowledge, which is rather an influence on capital. Participants stated that they had gained knowledge in key areas, for example in knowing the types of facilities that are available in higher education and the opportunities it can offer.

One parent said:

"Myself and my husband never attended university. We have mediocre jobs. We both said that seeing the talks inspired us to try to encourage our children to attend university, not just for the qualifications but that it can also open up so many doors, giving them the opportunity to travel and meet people and see amazing things.”

This point is emphasised by the fact that words signifying 'opportunity' were the single most common class in our word frequency search.

The information that attendees gathered was not mediated by others, as in traditional 'hot' information, and therefore produces an accurate impression of factors such as what a university campus looks like, what a lecture theatre is and what facilities a university might have - knowledge that may not be already held by parents from more deprived areas.

The information gleaned may be more trusted than typical 'cold' information such as presentations on open days or prospectuses; the fact that the festival does not explicitly promote higher education is an important factor in building this trust in the information gathered. For example, one 
respondent commented: "It was encouraging to see young people being engaged by staff and presenters. No hard sell either.” The lack of any explicit recruitment agenda allows attendees to trust the 'ambient information' they gather during the day.

As the children attending the event are for the most part of primary age, parents are being given the opportunity to gather knowledge about university before it is needed. This knowledge may later enable them to offer the advice which Bailey (Bailey, 2015: 185) found that they craved.

An important point to note is that ambient information is, by definition, available to all. Although it appears to be disproportionately useful to families with less existing capital, it is accessed without the need to 'single out' groups for special treatment. Its use therefore avoids any 'othering' of families and is removed from potentially harmful discourses of 'deficit thinking'.

The positive findings outlined above come with one very important caveat attached, arising from the attendance data which showed that participants from areas of high deprivation were underrepresented at the festival. The skew towards attendees from less deprived groups, and particularly towards graduates, highlights the fact that universities hoping to use broad-based events to widen participation must make strenuous efforts to attract the target audience to attend in the first place. However this must be done in such a way as to not detract from the fun and informal nature of the event.

\section{Conclusions}

This case study set out to investigate what impact, if any, attendance at a university-based science festival had on parents' attitudes towards their children progressing to higher education. We posited that the 'ambient information' gathered at such an event would be trusted by parents from deprived areas as it came without the perceived recruitment baggage of more formal campus-based events such as open days. We further posited that immersion in a university setting, both in terms of the physical environment and encounters with staff and students, could affect parental and family habitus, or feelings of what is 'my place', as well as their stocks of knowledge about higher education.

We found that parents from areas of greater deprivation underwent a more significant shift in attitude towards university than those from less deprived areas. Themes that arose included the effect of visiting the physical campus, and the impression of accessibility that was created by attendance, both of which have the ability to shift individual and family habitus. We also found that crucial knowledge, such as of what courses were available and what 
sort of facilities a university has, was gleaned during the festival, thus impacting capital.

Many of these parents spoke of their high aspirations for their children's educational future; however the experience of visiting the LSF appears to have bolstered, or reinforced, these positions, as well as making university seem 'real'. The experience appears in some respondents to have increased parental expectation to match already high aspiration, a factor which has the potential to significantly influence their child's academic future.

Whilst these are positive findings suggesting that events such as campusbased science festivals can have measurable impacts on widening participation objectives, it is important to note that attendance at such events is not evenly distributed across socioeconomic groupings, with families from more deprived areas and those headed by non-graduates underrepresented.

The policy implication of these findings is therefore that there is widening participation value in broad-based, non-targeted programmes which aim to use concepts of 'fun' and 'enjoyment' to attract families on to campuses in a neutral way. The challenge for higher education institutions is to improve attendance at such events by members of under-represented groups without losing the overriding principle that recruitment is not an overt objective.

It would be interesting to examine these findings further by studying the impacts of a range of campus-based events in other institutional settings, both in the English context and more broadly. There are therefore opportunities for future research in order to deepen our understanding of parents' and families' experiences of such events and the ambient information gathered.

\footnotetext{
${ }^{\mathrm{i}}$ https://www.legislation.gov.uk/ukpga/2017/29/part/1/crossheading/access-andparticipation

ii https://www.sciencefestival.co.uk/what-we-do

iii $\underline{\text { http://sciencefestivals.uk/the-uk-science-festivals-network-in-2015 }}$

${ }^{\text {iv }}$ www.ons.gov.uk/census/2011census

${ }^{\vee}$ Names of focus group participants have been changed.

https://www.gov.uk/government/uploads/system/uploads/attachment_data/file/465791/Engl ish_Indices_of_Deprivation_2015_-_Statistical_Release.pdf
} 


\section{References}

Archer, L., Dewitt, J., Osborne, J., Dillon, J., Willis, B. and Wong, B. (2012) 'Science Aspirations, Capital, and Family Habitus: How Families Shape Children's Engagement and Identification With Science', American Educational Research Journal, 49, 5: 881-908.

Archer, L., Hutchings, M. and Ross, A. (2003) Higher Education and Social Class: Issues of Exclusion and Inclusion, London: RoutledgeFalmer.

Archer, L., Osborne, J., DeWitt, J., Dillon, J., Wong, B. and Willis, B. (2013) 'Young people's science and career aspirations, age 10-14', November 2013, at

https://www.kcl.ac.uk/sspp/departments/education/research/aspires/ASPIRES -final-report-December-2013.pdf (accessed: 12 January 2018).

Bailey, W. (2015) 'Social deprivation and widening participation : the continuing power of local culture', March 2015, at http://eprints.hud.ac.uk/id/eprint/24267/ (accessed: 12 January 2018).

Ball, S. J. and Vincent, C. (1998) "'I Heard It on the Grapevine": "hot" knowledge and school choice', British Journal of Sociology of Education, 19, 3: 377-400.

Bultitude, K. (2014) 'Science festivals: Do they succeed in reaching beyond the "already engaged”?' Journal of Science Communication, 13, 4: 1-3.

Bultitude, K., McDonald, D. and Custead, S. (2011) 'The Rise and Rise of Science Festivals: An international review of organised events to celebrate science', International Journal of Science Education, Part B: Communication and Public Engagement, 1, 2: 165-188.

Bultitude, K. and Sardo, A. M. (2012) 'Leisure and Pleasure: Science events in unusual locations', International Journal of Science Education, 34, 18: 27752795.

Connor, H. and Dewson, S., (2001) 'Social Class and Higher Education: Issues Affecting Decisions on Participation by Lower Social Class Groups', Department for Education and Employment Research Report 267, March 2001, at http://dera.ioe.ac.uk/4621/1/RR267.pdf (accessed: 12 January 2018).

Department for Education (2017) 'Widening Participation in Higher Education, England, 2014/15 age Cohort', 3 August 2017, at https://www.gov.uk/government/uploads/system/uploads/attachment_data/file 635103/SFR39-2017-MainText.pdf (accessed: 12 January 2018).

Dodgson, R. (2004) 'Parents and higher education in the north-east of England: Attitudes, concerns, influence and engagement', Journal of Access Policy and 
Practice, 2, 1: 5-23.

Fogg-Rogers, L., Bay, J., Burgess, H. and Purdy, S. (2015) '"Knowledge Is Power": A Mixed-Methods Study Exploring Adult Audience Preferences for Engagement and Learning Formats Over 3 Years of a Health Science Festival', Science Communication, 37, 4: 419-451.

Greaves, E. and Crawford, C. (2013) 'A comparison of commonly used socioeconomic indicators: their relationship to educational disadvantage and relevance to Teach First', Institute for Fiscal Studies Report R79, January 2013, at https://www.ifs.org.uk/comms/r79.pdf (accessed: 12 January 2018).

Jensen, E. and Buckley, N. (2014) 'Why people attend science festivals: Interests, motivations and self-reported benefits of public engagement with research', Public Understanding of Science, 23, 5: 557-573.

Johnson, R. B. and Onwuegbuzie, A. J. (2004) 'Mixed Methods Research: A Research Paradigm Whose Time Has Come', Educational Researcher, 33, 7: $14-26$.

Kennedy, E. B., Jensen, E. A. and Verbeke, M. (2017) 'Preaching to the scientifically converted: evaluating inclusivity in science festival audiences', International Journal of Science Education, Part B, 8, 1: 14-21.

Khattab, N. (2015) 'Students' aspirations, expectations and school achievement: What really matters?', British Educational Research Journal, 41, 5: 731-748.

Krueger, R. A. and Casey, M. A. (2015) Focus Groups: A Practical Guide for Applied Research, Los Angeles: SAGE.

Pugsley, L. (1998) 'Throwing Your brains at it: Higher education, markets and choice', International Studies in Sociology of Education, 8, 1: 71-92.

Reay, D. and Ball, S. J. (1998) '“Making their Minds Up”: family dynamics of school choice', British Educational Research Journal, 24, 4: 431-448.

Riise, J. and Alfonsi, L. (2014) 'From liquid nitrogen to public engagement and city planning: The changing role of science events', Journal of Science Communication, 13, 4: 1-8.

Rose, K. M., Korzekwa, K., Brossard, D., Scheufele, D. A. and Heisler, L. (2017) 'Engaging the Public at a Science Festival', Science Communication, 39, 2: 250-277.

Slack, K., Mangan, J., Hughes, A. and Davies, P. (2014) "“Hot”, “cold” and "warm" information and higher education decision-making', British Journal of Sociology of Education, 35, 2: 204-223. 
Smit, R. (2012) 'Towards a clearer understanding of student disadvantage in higher education: Problematising deficit thinking', Higher Education Research \& Development, 31, 3: 369-380.

Swartz, D. L. (2002) 'The Sociology of Habit: The Perspective of Pierre Bourdieu', The Occupational Therapy Journal of Research, 22, 1 (supplement): 61-69.

Valencia, R. R. (1997) The evolution of deficit thinking: Educational thought and practice, London: Falmer Press.

Whitty, G., Hayton, A. and Tang, S. (2015) 'Who you know, what you know and knowing the ropes: a review of evidence about access to higher education institutions in England', Review of Education, 3, 1: 27-67.

Wiehe, B. (2014) 'When science makes us who we are: Known and speculative impacts of science festivals', Journal of Science Communication, 13, 4: 1-7. 